\title{
A Compact Dual-Band Circularly Polarized Antenna with Wide HPBWs for CNSS Applications
}

\author{
Chao Li $(\mathbb{D}$, Fu-Shun Zhang, Fan Zhang, and Kaiwen Yang \\ National Laboratory of Antennas and Microwave Technology, Xidian University, Xi'an, Shaanxi 710071, China \\ Correspondence should be addressed to Chao Li; lichao972@126.com
}

Received 9 November 2017; Revised 22 December 2017; Accepted 26 December 2017; Published 4 March 2018

Academic Editor: Ikmo Park

Copyright $\odot 2018$ Chao Li et al. This is an open access article distributed under the Creative Commons Attribution License, which permits unrestricted use, distribution, and reproduction in any medium, provided the original work is properly cited.

\begin{abstract}
A compact dual-band circularly polarized antenna with wide half-power beamwidths (HPBWs) for compass navigation satellite system applications is proposed in this paper. The CP radiation is realized by arranging four compact dual-band inverted-F monopoles symmetrically to the center point, where the four monopoles are excited with a $90^{\circ}$ phase offset through a compact sequential-phase feeding network. The compactness of the dual-band inverted-F monopole is realized by inserting two chip inductors in the horizontal portion of the monopole. The overall dimension of the antenna is only $0.211 \lambda_{0} \times 0.211 \lambda_{0} \times 0.057 \lambda_{0}$, where $\lambda_{0}$ is the corresponding free-space wavelength at $1.268 \mathrm{GHz}$. Experimental results show that the proposed antenna exhibits two overlapped impedance and axial ratio bandwidths of $50 \mathrm{MHz}(1.236-1.286 \mathrm{GHz})$ and $40 \mathrm{MHz}(1.532-1.572 \mathrm{GHz})$. Wide HPBWs of about $120^{\circ} / 125^{\circ}$ and $121^{\circ} / 116^{\circ}$ (XOZ/YOZ planes) at center frequencies $(1.268,1.561 \mathrm{GHz}$ ) of the CNSS-2 B3 and B1 bands are obtained, respectively. With these good performances, the antenna can be a good candidate for CNSS applications.
\end{abstract}

\section{Introduction}

In recent years, satellite navigation systems have been widely used in human life for civilian and military applications. Among them all, the compass navigation satellite system (CNSS) has attracted more and more attentions due to the navigation and positioning services compatible with other systems. In some applications of the CNSS-2, terminals are required to operate at $\mathrm{B} 3(1.268 \mathrm{GHz} \pm 10 \mathrm{MHz})$ and $\mathrm{B} 1(1.561 \mathrm{GHz} \pm 2 \mathrm{MHz})$ bands with a right-hand circular polarization (RHCP) radiation pattern. Nevertheless, with the dimensions of the CNSS terminals getting smaller, a compact dual-band CP antenna covering both the bands is highly demanded.

Many dual-band circularly polarized (CP) antennas with compact dimensions have been reported, and they can be divided into three types in summary. The microstrip antenna is the most common type used for dual-band GNSS applications. Various kinds of techniques are used to reduce the antenna dimension, such as adopting highpermittivity substrates in $[1-3]$, grounding the central patches surrounded by four square-ring-shaped slots $\left(0.396 \lambda_{0} \times 0.396 \lambda_{0} \times 0.048 \lambda_{0}\right)$ in [4], loading two shorting probes in parallel $\left(0.23 \lambda_{0} \times 0.23 \lambda_{0} \times 0.07 \lambda_{0}\right)$ in [5], utilizing the structure of a split patch surrounded by a split ring $\left(0.289 \lambda_{0} \times 0.289 \lambda_{0} \times 0.099 \lambda_{0}\right)$ in [6], and using truncated corner square patch radiators stacked over a reactive impedance surface to reduce the electrical size of the antenna for lower band in $[7,8]$. The ring-shaped patch antenna is another way to achieve a compact size. In $[9,10]$, the fundamental modes of the ring resonators are excited by employing meandering slots and integrating a locally grounded coupler, respectively, to reduce their dimensions. Concentric annular rings $\left(0.259 \lambda_{0} \times 0.259 \lambda_{0} \times 0.048 \lambda_{0}\right)$ in [11], rectangular rings $\left(0.231 \lambda_{0} \times 0.231 \lambda_{0} \times 0.084 \lambda_{0}\right)$ in [12], and meandered-lineshaped rings $\left(0.201 \lambda_{0} \times 0.201 \lambda_{0} \times 0.076 \lambda_{0}\right)$ in [13] are printed on the same layer or different layers, respectively, to obtain reduced antenna dimensions. Apart from the two types mentioned above, various kinds of compact dualband CP crossed-dipole antennas have been reported. In [14], asymmetrically barbed arrowheads and printed inductors are inserted in each dipole arm to reduce the antenna dimension. In $[15,16]$, complementary split-ring resonators and four-arm curl of different arm lengths are used to achieve 


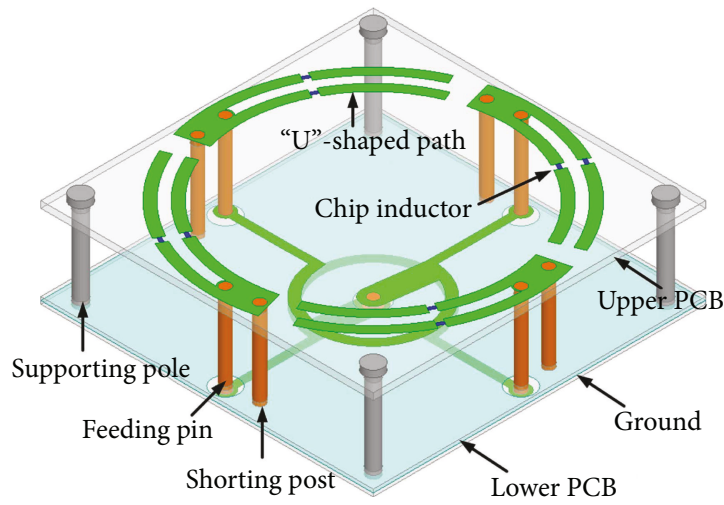

(a)

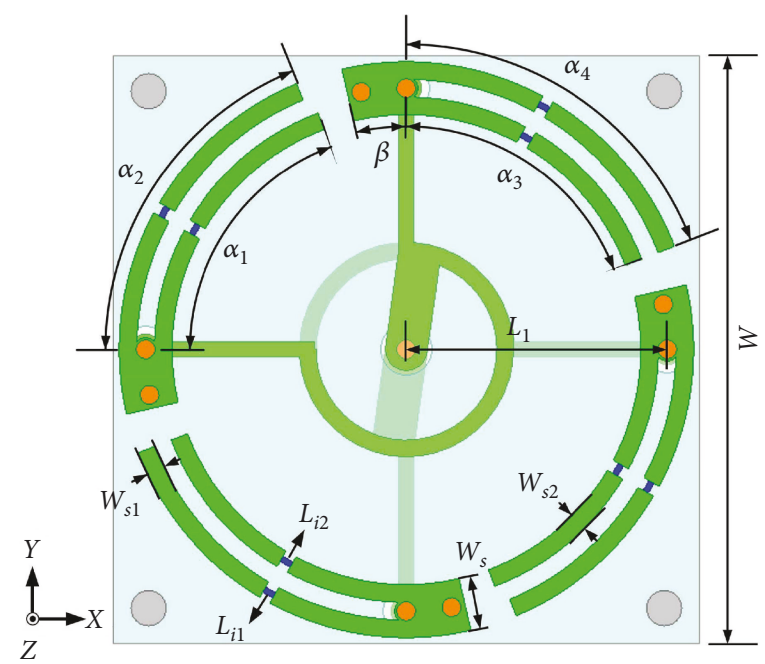

(b)

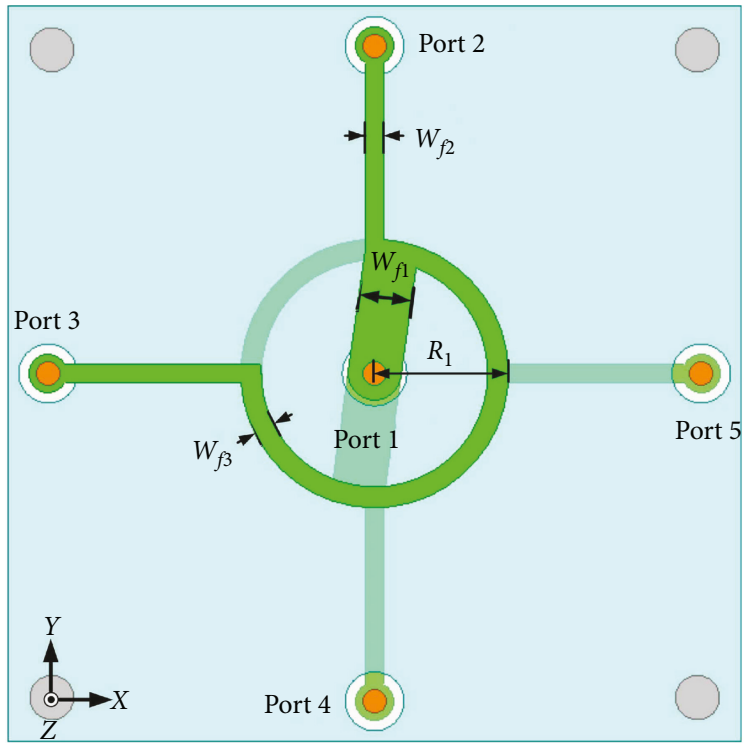

(d)

FIGURE 1: Geometry of the proposed antenna: (a) 3D view; (b) top view; (c) side view; (d) feeding network.

dual-band operations and compact dimensions. However, the profiles of these crossed-dipole antennas are relatively high due to the generally needed metal cavities in them. Although the dimensions of the antennas are reduced by these techniques, they may suffer from complicated structures and narrow radiation patterns with HPBWs of less than $100^{\circ}$ in general.

Wide half-power beamwidths (HPBWs) are very valuable in CNSS applications in order to improve the coverage area and stabilize the receiving signal. Many studies have been done to broaden the HPBWs of the antenna, such as extending the substrate beyond the ground plane with HPBWs of $130^{\circ}$ in [17], loading auxiliary radiators with HPBWs of $90^{\circ}$ in [18], loading with curved microstrip resonant structure with HPBWs of $150^{\circ}$ in [19], utilizing the curved dipoles and ground planes with HPBWs of $150^{\circ}$ in
[20], and adopting various kinds of conducting wall or cavity with HPBWs of greater than $100^{\circ}$ in [21-24] which is the most common way. Nevertheless, the antennas mentioned above have relatively large dimensions, and most of them focus on single-band work.

In this paper, a compact dual-band $\mathrm{CP}$ antenna with wide HPBWs is proposed. Four compact inverted-F monopoles are arranged symmetrically to the center point and fed by a compact sequential-phase (SP) feeding network to get the $\mathrm{CP}$ radiation. With the use of the shorting technique and chip inductors, the compactness of the dual-band inverted-F monopole is obtained. The overall dimension of the antenna is only $0.211 \lambda_{0} \times 0.211 \lambda_{0} \times 0.057 \lambda_{0}$, where $\lambda_{0}$ is the corresponding free-space wavelength at $1.268 \mathrm{GHz}$. The two impedance bands $\left(\left|S_{11}\right|<-10 \mathrm{~dB}\right)$ are $72 \mathrm{MHz}$ $(1.236-1.308 \mathrm{GHz})$ and $96 \mathrm{MHz}(1.52-1.616 \mathrm{GHz})$, while 


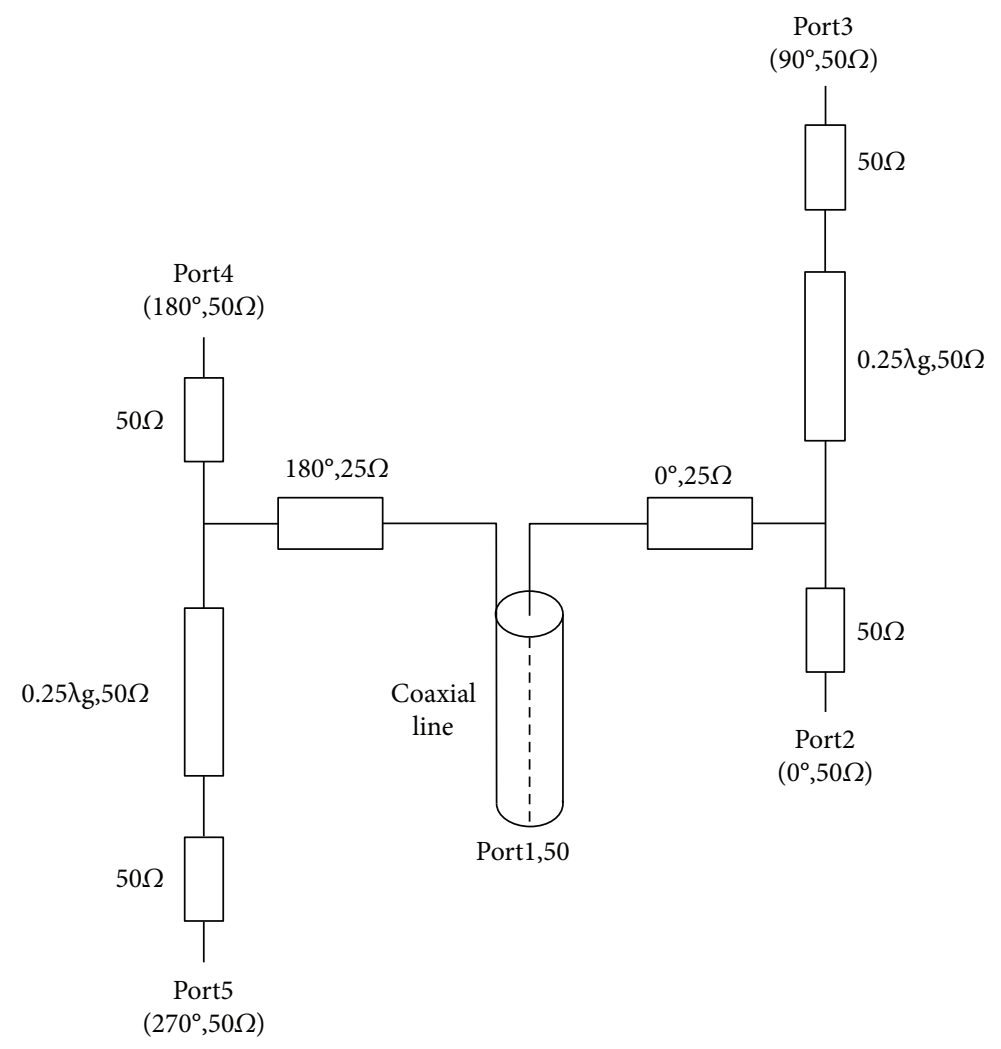

FIGURE 2: Equivalent-circuit model of the feeding network.

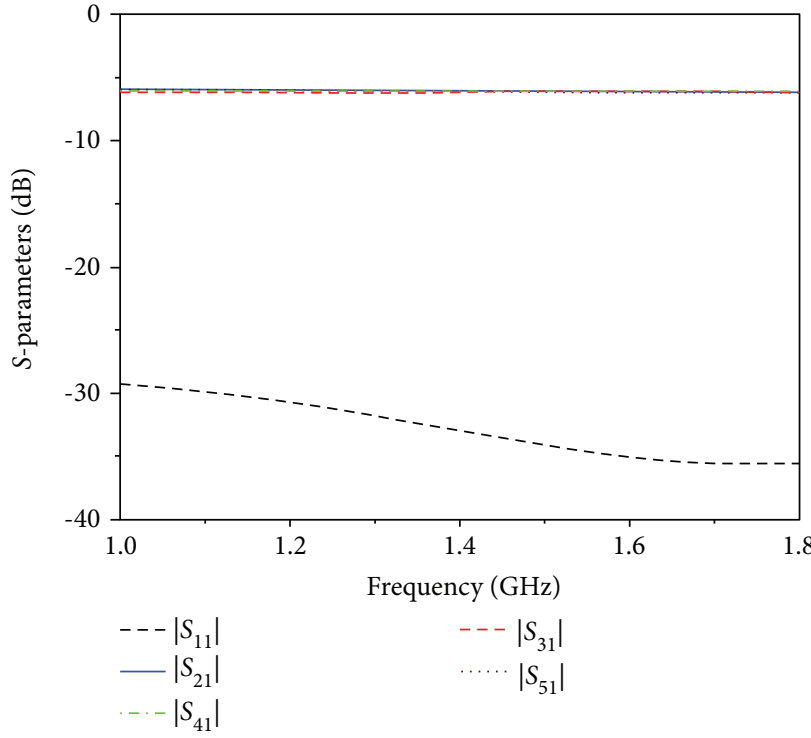

(a)

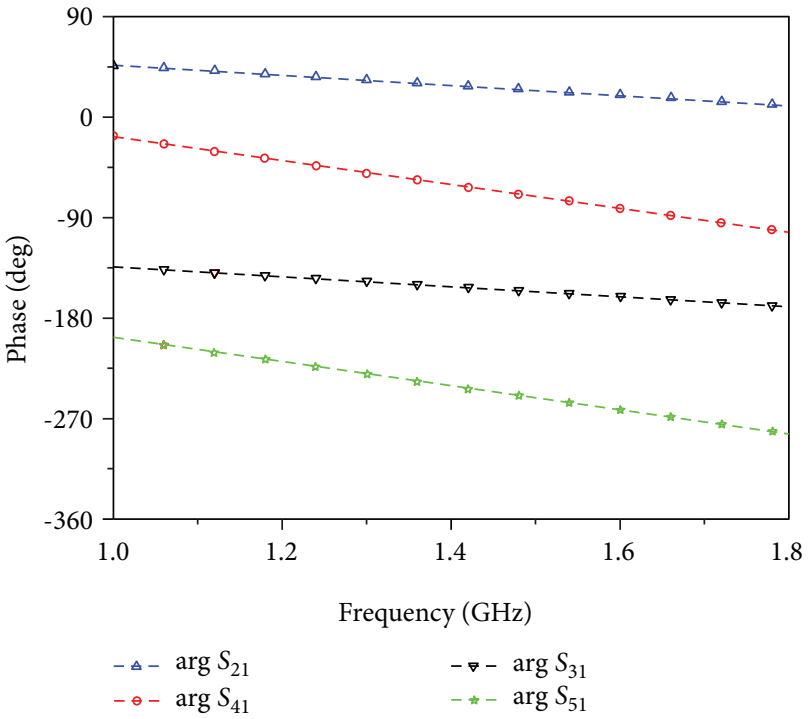

(b)

FIGURE 3: Simulated (a) S-parameters and (b) transmission phases of the SP feeding network.

the corresponding axial ratio $(\mathrm{AR})$ bands $(\mathrm{AR}<3 \mathrm{~dB})$ are $54 \mathrm{MHz} \quad(1.232-1.286 \mathrm{GHz})$ and $40 \mathrm{MHz} \quad(1.532-$ $1.572 \mathrm{GHz}$ ), covering the CNSS-2 B3 and B1 bands, respectively. Meanwhile, the HPBWs at $1.268 \mathrm{GHz}$ and $1.561 \mathrm{GHz}$ are both greater than $115^{\circ}$. Details of the proposed antenna design are presented in Section 2.

\section{Antenna Geometry and Design Process}

2.1. Antenna Geometry. The geometry of the proposed antenna is shown in Figure 1. The antenna is composed of three parts: the upper printed circuit board (PCB), the lower $\mathrm{PCBs}$ (including two substrates), and the middle connecting 

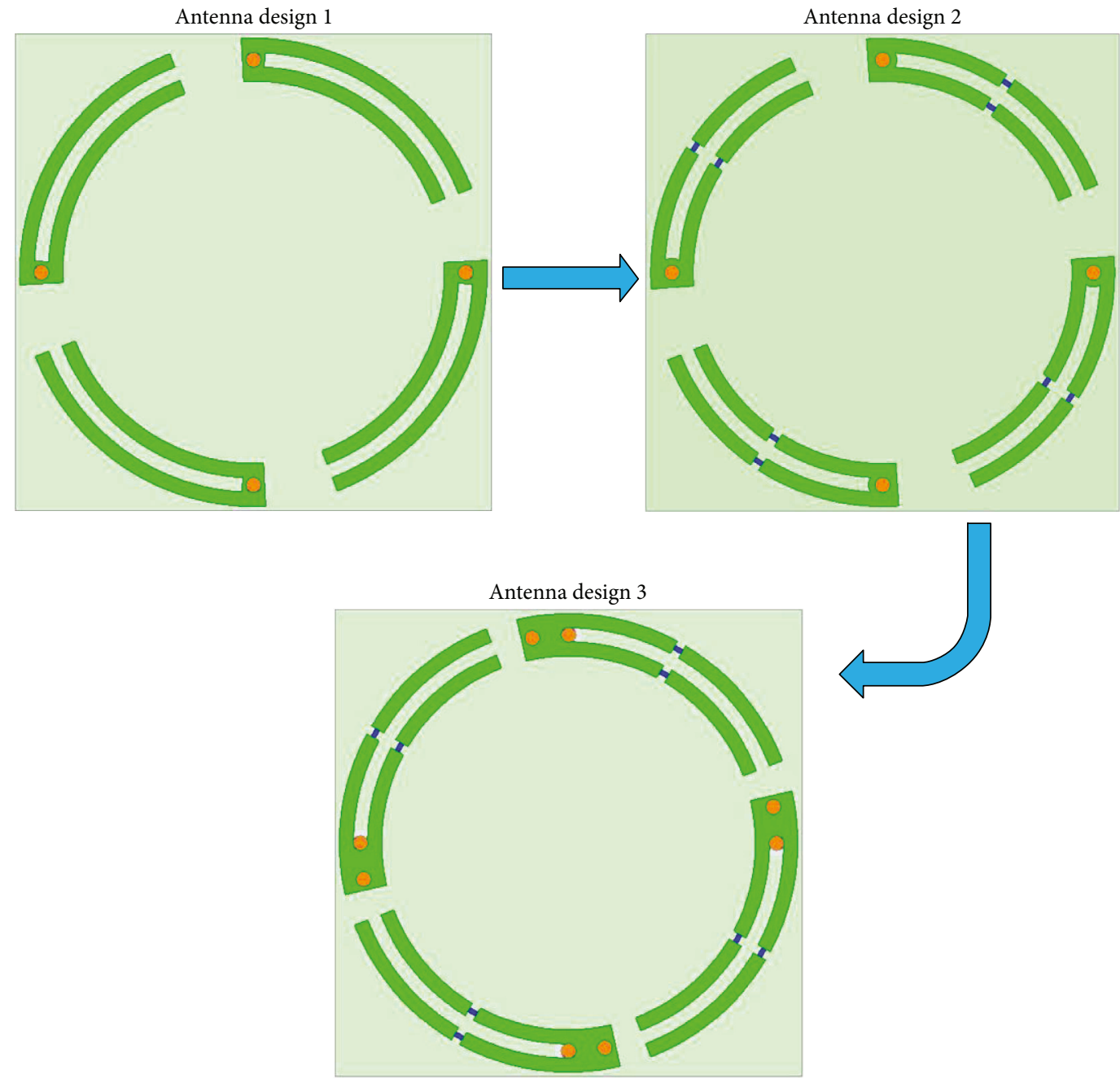

FIgURE 4: The design process of the proposed antenna.

structures (including feeding pins, metallic shorting posts, and nonmetallic supporting poles).

The upper PCB is a $1 \mathrm{~mm}$ thick FR4 substrate with a relative permittivity of 4.4. Four " $U$ "-shaped patches (with radius of $L_{1}$ ) composed of two connected arc-shaped arms are etched on the top layer of the upper substrate. The two arc-shaped arms with different radius and angles are resonant at different frequencies. Two chip inductors with different inductance $\left(L_{i 1}\right.$ and $\left.L_{i 2}\right)$ are inserted in the two arms of the "U"-shaped patch, respectively. Each upper patch is connected to the feeding network by a feeding pin (with a radius of $0.8 \mathrm{~mm}$ ) and is shorted to the metal ground by a metallic shorting post (with a radius of $0.8 \mathrm{~mm}$ ) at the initial portion (with angle $\beta$ ). Thus, the " $U$ "-shaped patch can be regarded as a dual-band inverted-F monopole. The inverted-F monopoles are arranged symmetrically to the center point of the antenna and excited with $90^{\circ}$ phase offsets through a compact SP feeding network. Four nonmetallic poles are employed as the structural support between the upper and lower PCBs.

The lower PCBs are composed of two substrates, and both of them are $0.5 \mathrm{~mm}$ thick PTFE substrates with a relative permittivity of 2.65. The SP feeding network is composed of

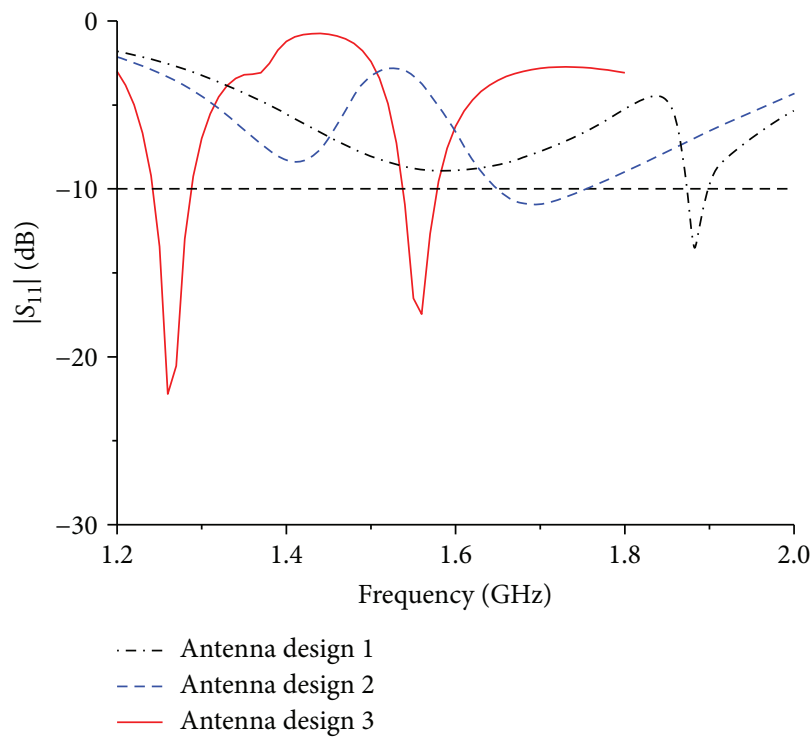

FIGURE 5: The simulated $\left|S_{11}\right|$ of the three antenna designs. 

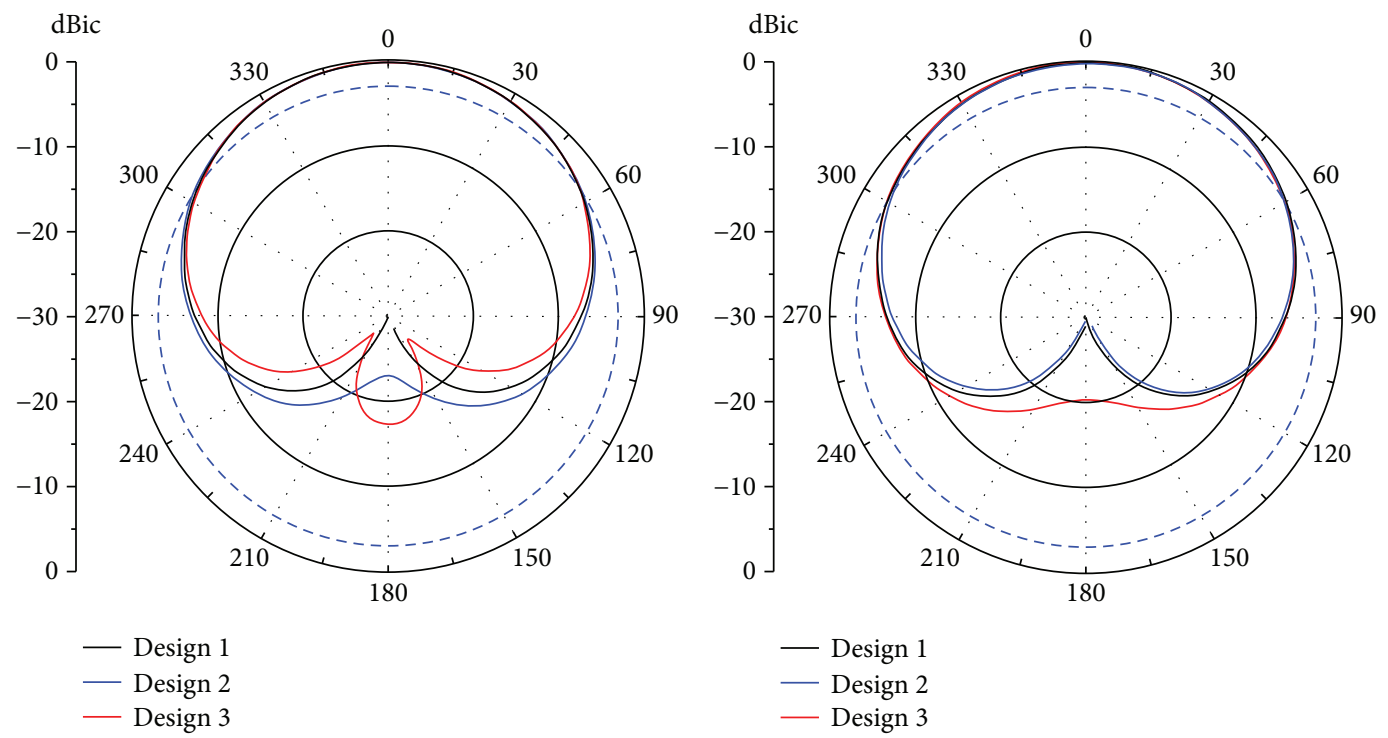

(a)

(b)

FIgURE 6: Normalized radiation patterns of the three designs at (a) low band and (b) high band.

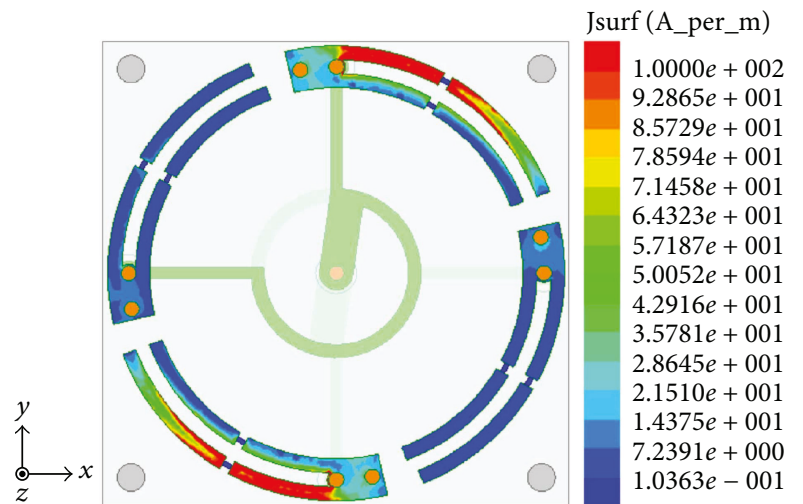

(a)

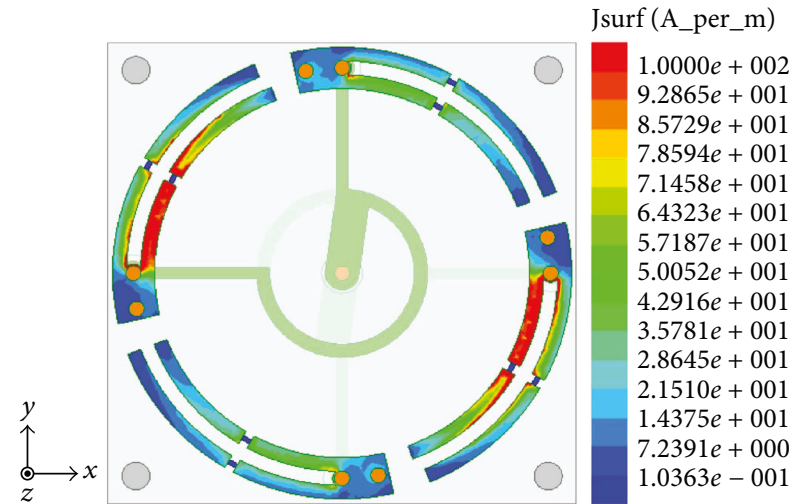

(b)

FIGURE 7: Simulated current distributions of the proposed antenna at (a) $1.268 \mathrm{GHz}$ and (b) $1.561 \mathrm{GHz}$.

three layers on the two substrates. Figure $1(\mathrm{~d})$ shows the layout of the feeding lines of the SP feeding network. A $50 \Omega$ coaxial line is used as the input feeding structure, and the middle layer is used as the ground plane. The outer conductor of the coaxial line is connected to the bottom layer, whereas the inner conductor is connected to the top layer. A circular aperture at the center point is removed from the ground plane on the middle layer. Unlike the feeding network in [25], the microstrip transmission lines are positioned on the opposite sides of the ground plane rather than on the same side. Two concentric vacant-quarter rings are etched on the top and bottom layers, respectively, with the same outer radius $R_{f}$ and microstrip transmission line widths $\left(W_{f 1}, W_{f 2}\right.$, and $\left.W_{f 3}\right)$.

The equivalent-circuit model of the SP feeding network is shown in Figure 2. Based on the out-of-phase property between the inner and outer conductors of the coaxial line, a stable $180^{\circ}$ phase difference between the top and bottom layers is achieved. In order to achieve impedance matching,

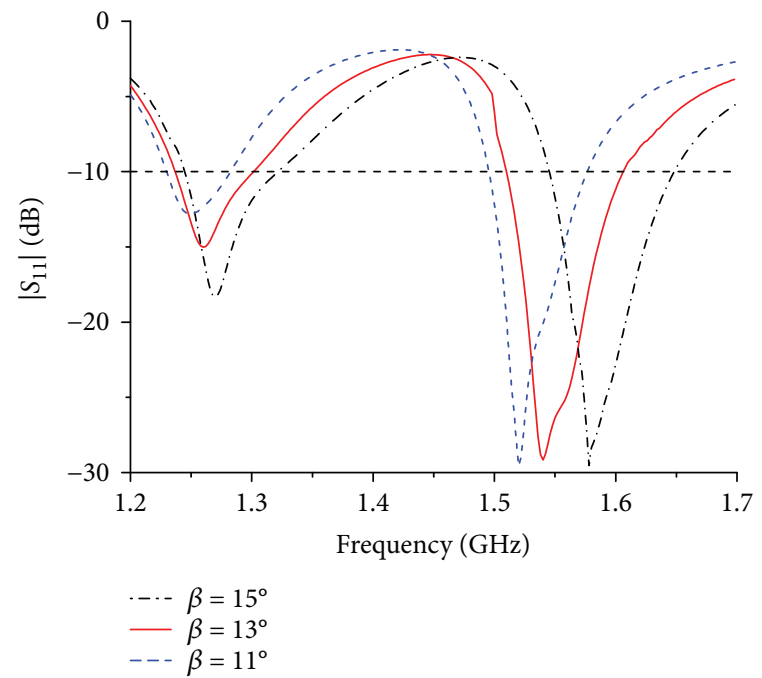

Figure 8: Simulated $\left|S_{11}\right|$ for various values of $\beta$. 


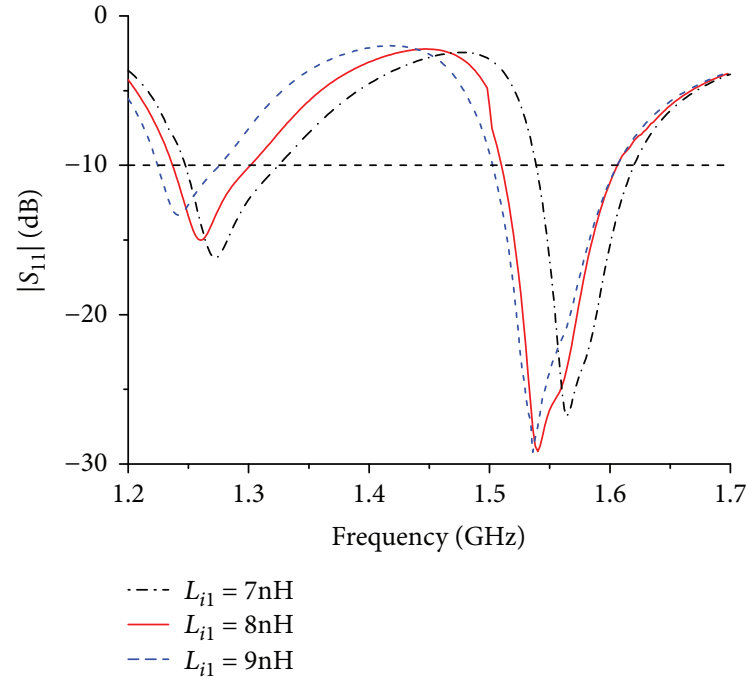

(a)

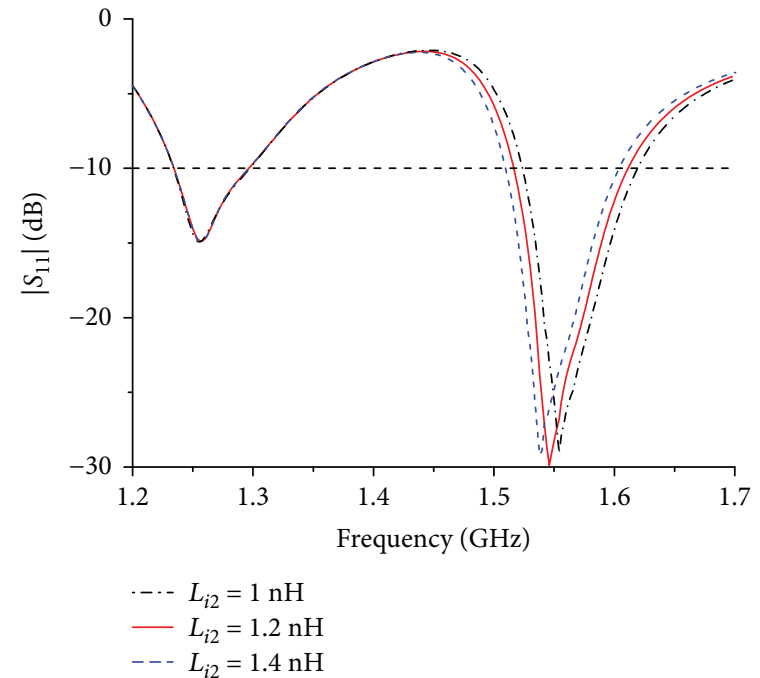

(b)

FIGURE 9: Simulated $\left|S_{11}\right|$ for various values of (a) $L_{i 1}$ and (b) $L_{i 2}$.

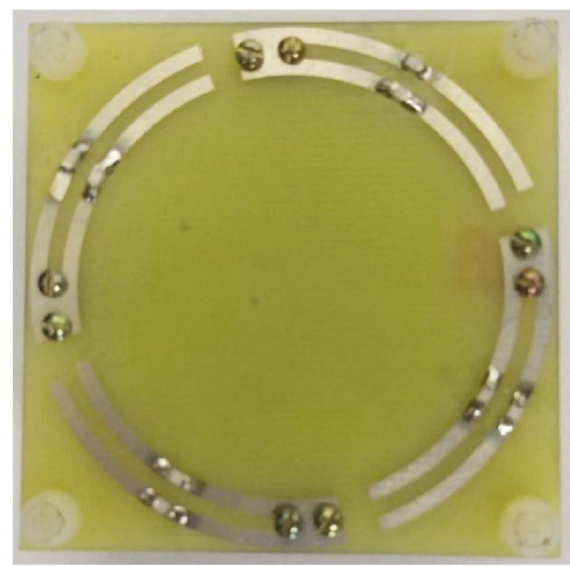

(a)

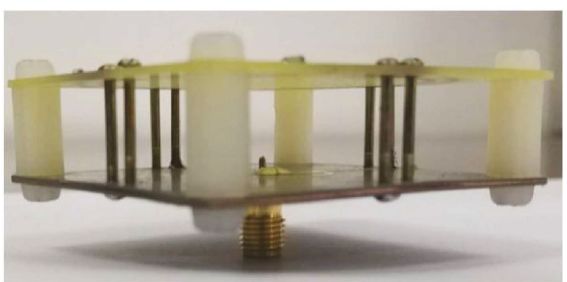

(b)

Figure 10: Prototype of the proposed antenna: (a) top view; (b) side view.

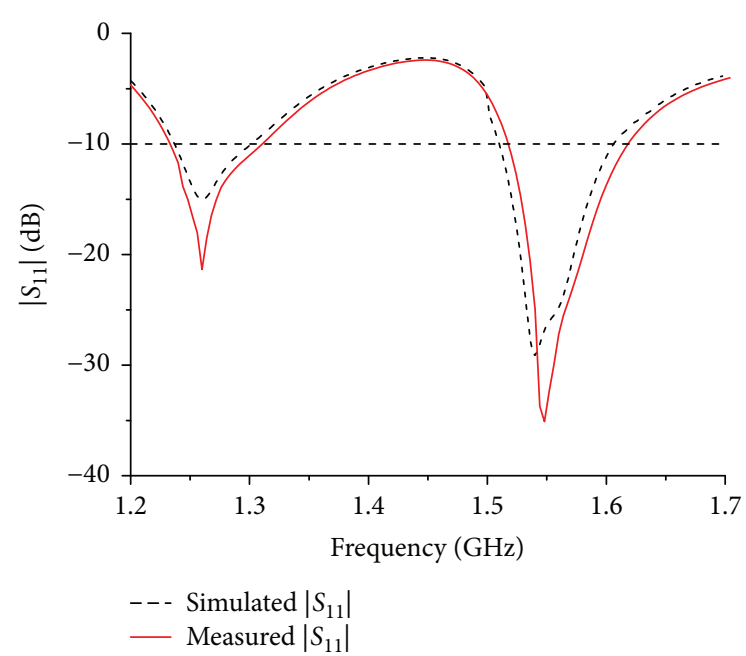

FIGURE 11: Simulated and measured $\left|S_{11}\right|$ of the proposed antenna.

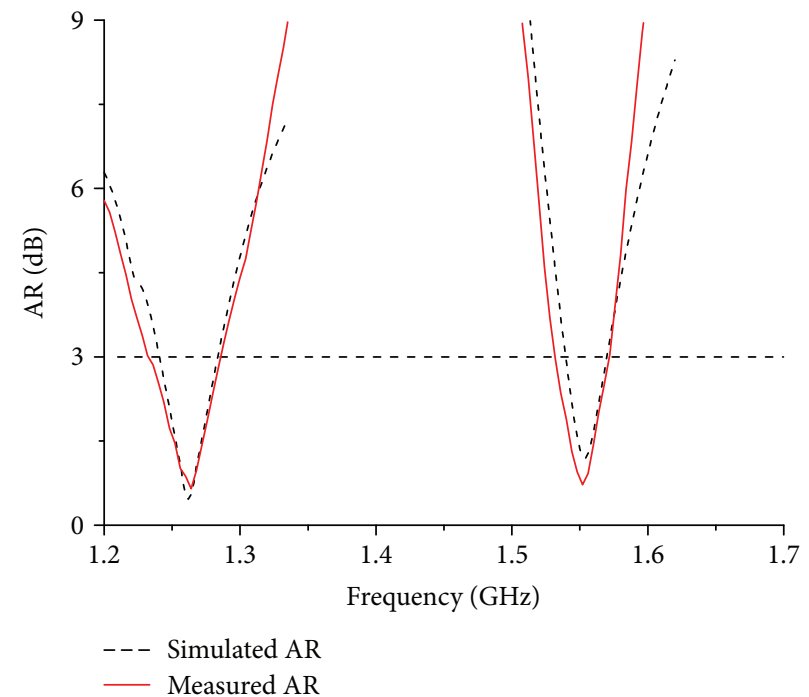

FIGURE 12: Simulated and measured AR of the proposed antenna. 

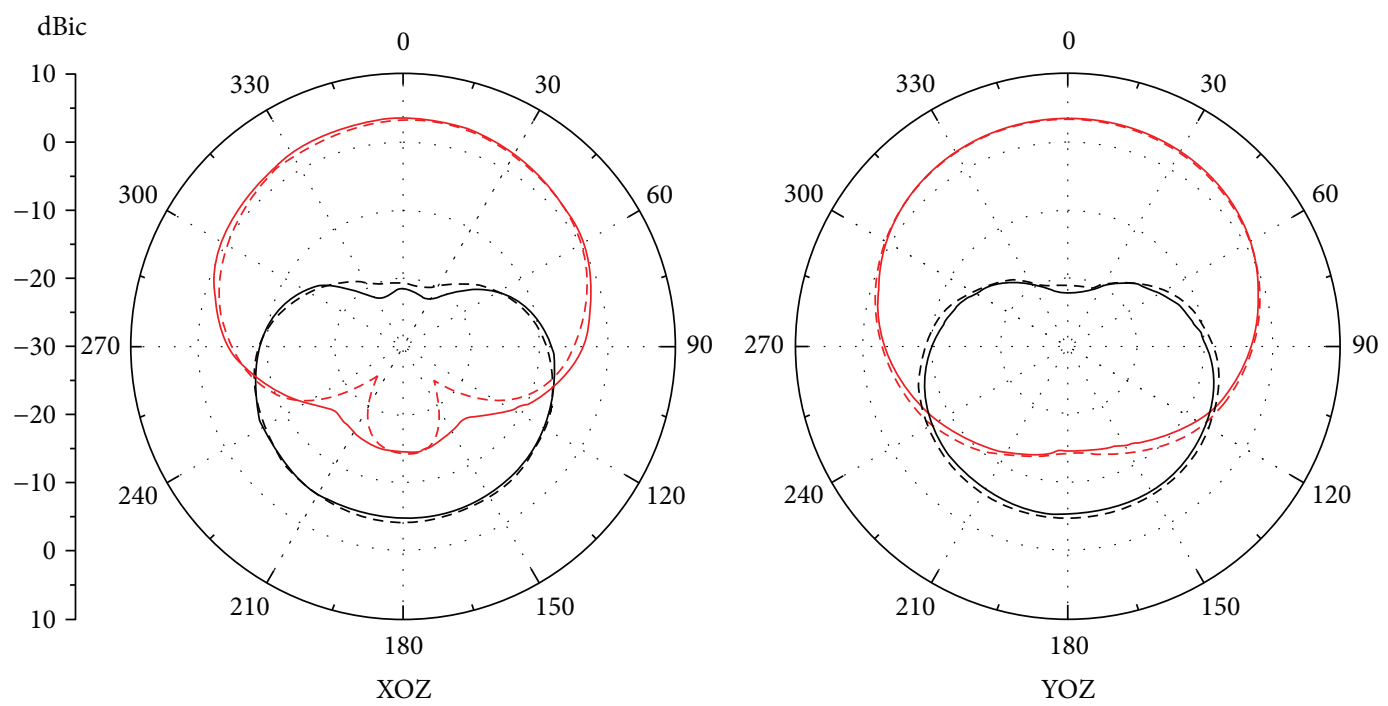
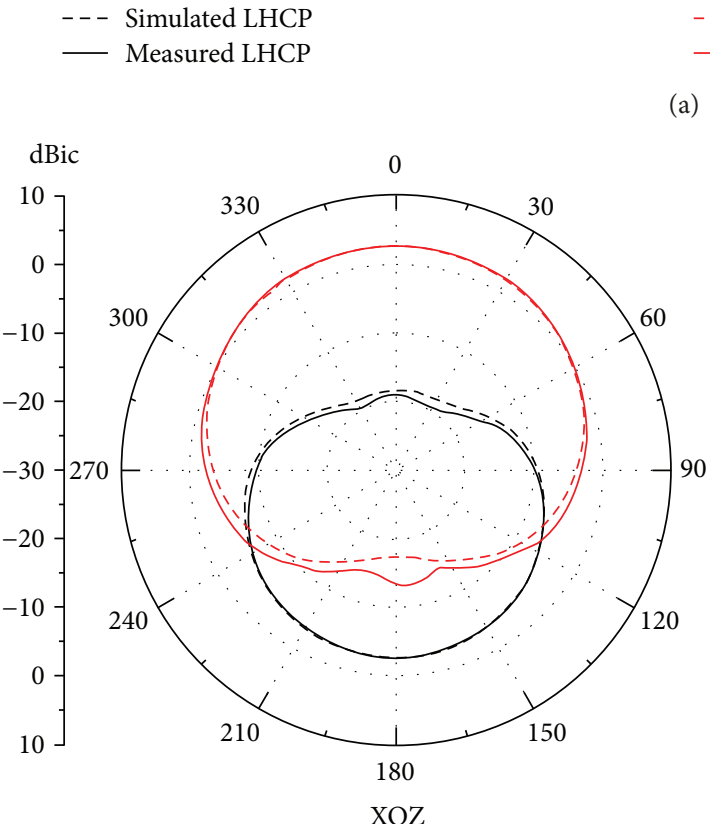

(a)
- - - Simulated RHCP

- Measured RHCP

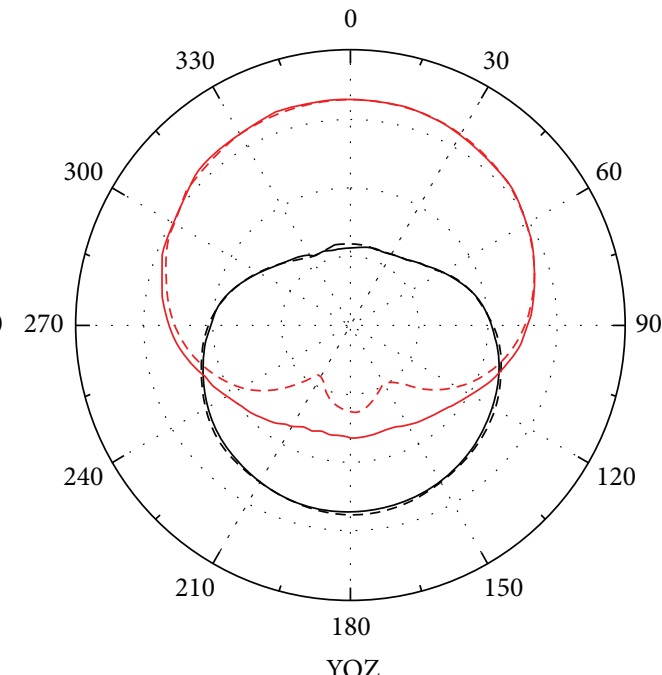

- - - Simulated RHCP

— Measured RHCP

(b)

FIGURE 13: Simulated and measured radiation patterns at (a) $1.268 \mathrm{GHz}$ and (b) $1.561 \mathrm{GHz}$.

the characteristic impedance of the microstrip transmission line with width $W_{f 1}$ near the feeding point is chosen as $25 \Omega$, while that of the lines with widths $W_{f 1}$ and $W_{f 2}$ is chosen as $50 \Omega$. The two concentric vacant-quarter rings are used as $90^{\circ}$ phase delay lines to achieve $90^{\circ}$ phase offsets between the four output ports.

Figure 3 shows the simulated $S$-parameters and transmission phases of the SP feeding network. As shown in Figure 3(a), the transmission coefficients (from $\left|S_{21}\right|$ to $\mid$ $\left.S_{51} \mid\right)$ are $-6.1 \pm 0.3 \mathrm{~dB}$, while the reflection coefficients at port $1\left(\left|S_{11}\right|\right)$ is below $-29 \mathrm{~dB}$ across the frequency range of $1.0-1.8 \mathrm{GHz}$. As shown in Figure 3(b), a phase difference of approximately $90^{\circ} \pm 5^{\circ}$ is achieved between the adjacent output ports in the frequency range of $1.2-$ $1.7 \mathrm{GHz}$.

The phase differences caused by the vacant-quarter rings are different at high and low bands. In order to compensate the phase difference between the two operating bands, the arc-shaped arm's lengths of the adjacent inverted-F monopoles are slightly different $\left(\alpha_{1} \neq \alpha_{3}, \alpha_{2} \neq \alpha_{4}\right)$, whereas the opposite monopoles are of the same dimension. The optimized antenna design parameters are as follows: $W=50 \mathrm{~mm}$, $W_{s}=4.5 \mathrm{~mm}, W_{s 1}=W_{s 2}=1.5 \mathrm{~mm}, W_{f 1}=3.6 \mathrm{~mm}, W_{f 2}=1.2 \mathrm{~mm}$, $W_{\beta 3}=1.4 \mathrm{~mm}, R_{f}=9.1 \mathrm{~mm}, L_{1}=22.2 \mathrm{~mm}, L_{i 1}=8.2 \mathrm{nH}, L_{i 2}=1.2 \mathrm{nH}$, $\alpha_{1}=69.5^{\circ}, \alpha_{2}=67.5^{\circ}, \alpha_{3}=\alpha_{4}=69^{\circ}, \beta=13^{\circ}, H=11.5 \mathrm{~mm}, H_{1}=1 \mathrm{~mm}$, and $\mathrm{H}_{2}=0.5 \mathrm{~mm}$. 


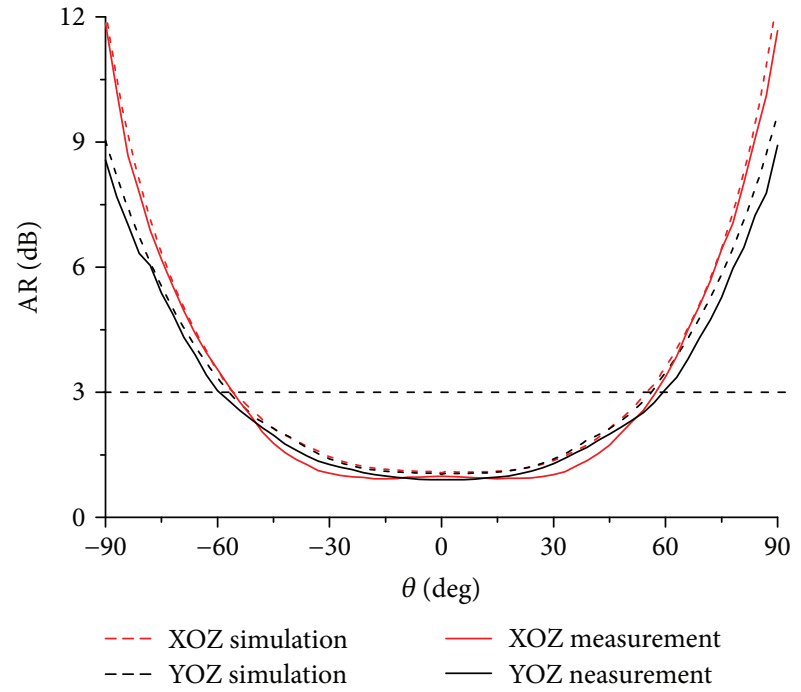

(a)

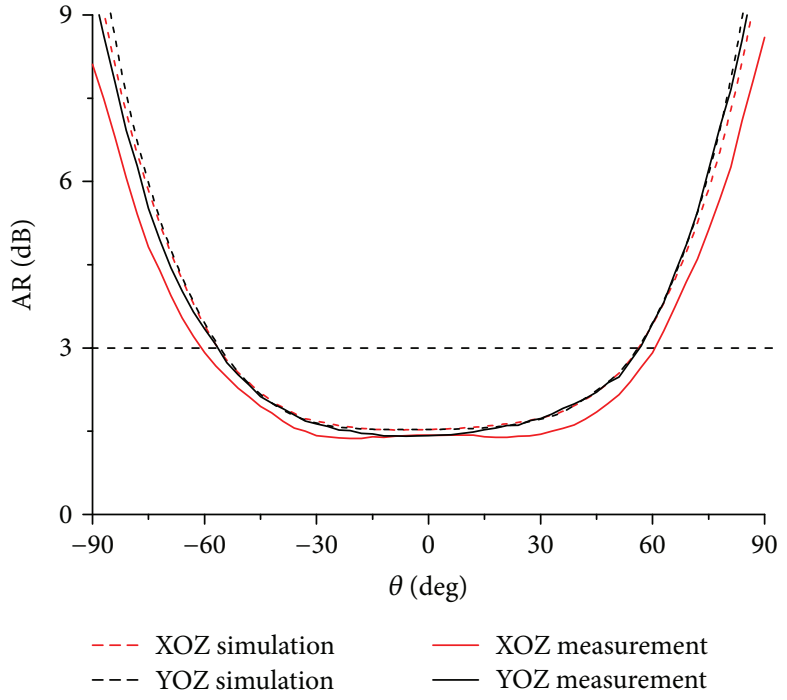

(b)

FIGURE 14: Simulated and measured AR at (a) $1.268 \mathrm{GHz}$ and (b) $1.561 \mathrm{GHz}$.

2.2. Antenna Design Process. Figure 4 shows the design process of the proposed antenna. The initial design (design 1) can be regarded as four "U"-shaped monopoles symmetrically arranged to the center point. Then two chip inductors with inductance $L_{i 1}$ and $L_{i 2}$ are inserted in both arms of the monopole antenna (design 2). Finally, the shorting load technique is used to achieve size reduction. An arc-shaped arm of angle $\beta$ and width $W_{s}$ is added to the connected portion of the "U"-shaped monopole and shorted to the ground by a metallic shorting post. After adopting the shorting load technique, the " $U$ "-shaped monopole is transformed into an inverted-F monopole antenna (design 3). All of the three designs use the same FR4 and PTFE substrates with the same dimension of $50 \times 50 \times 13.5 \mathrm{~mm}^{3}$.

The simulated $\left|S_{11}\right|$ of the three designs without the feeding network is shown in Figure 5. As can been seen from Figure 4, from design 1 to design 2, the resonant frequency shifts downwards. The main reason is that effective electric lengths of the arms are increased due to the inserted inductors. From design 2 to design 3, the resonant frequency decreases further because of the coupling capacitance between the shorting post and the antenna. It indicates that by using the shorting loaded technique and inserting chip inductors, the compactness of the antenna can be obtained.

Figure 6 shows the normalized RHCP radiation patterns of the three designs at the corresponding resonant frequencies of the low and high bands in the XOZ plane, respectively. As can be seen in Figure 6, all of the three designs have wide HPBWs greater than $110^{\circ}$. This phenomenon occurs mainly due to the vertical currents of the feeding pins and shorting posts and the relative shorter distance between the four monopoles.

Figure 7 shows the simulated current distributions of the proposed antenna at $1.268 \mathrm{GHz}$ and $1.561 \mathrm{GHz}$. It is obvious that at the low band, the current mainly focuses on the outer arc-shaped arm of the inverted-F monopole, whereas there is little current distributed on the inner one, while at the high band, the current mainly focuses on the inner one.

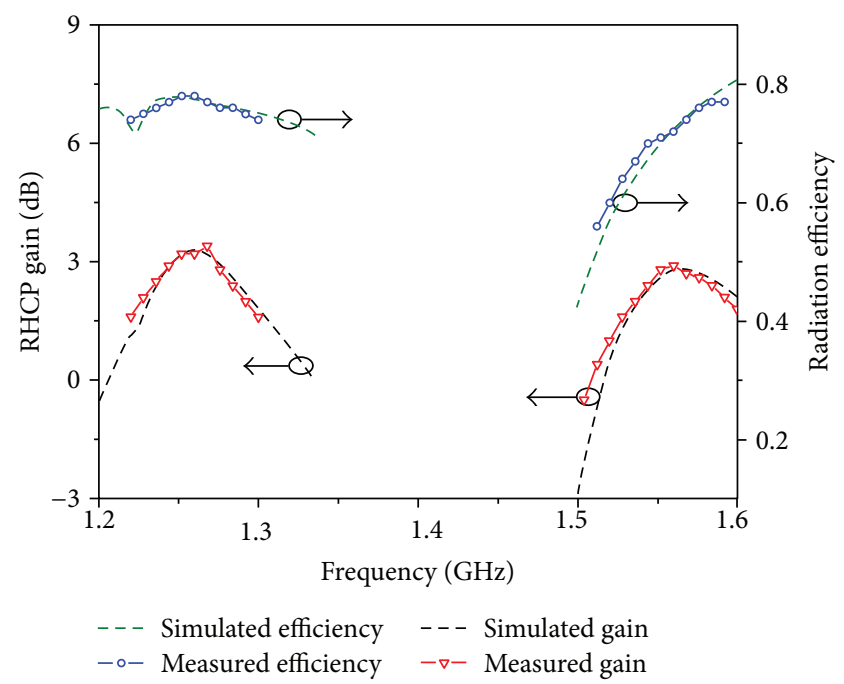

FIgURE 15: Simulated and measured boresight RHCP gains and radiation efficiencies.

\section{Parametric Study}

According to the antenna design process, the shorting loaded technique and inserted chip inductors are the main ways to reduce the antenna dimension; thus, the angle $\beta$ of the shorting arc-shaped arm and the inductance $\left(L_{i 1}\right.$ and $\left.L_{i 2}\right)$ of the two chip inductors have been studied.

Figure 8 shows the simulated $\left|S_{11}\right|$ with different values of angle $\beta$. As shown in Figure 8 , with $\beta$ varying from $15^{\circ}$ to $11^{\circ}$, the resonant frequencies at the low and high bands both decrease. It means that decreasing the length of the shorting arc-shaped arm can enhance the coupling capacitance between the shorting post and the antenna, which can reduce the antenna dimension.

The simulated $\left|S_{11}\right|$ with different values of $L_{i 1}$ and $L_{i 2}$ is shown in Figures 9(a) and 9(b), respectively. It can be seen 
TABLE 1: Performance comparison between the proposed antenna and the previous dual-band antennas.

\begin{tabular}{|c|c|c|c|c|c|c|}
\hline Antenna structure & Overall dimension & $\begin{array}{c}-10 \mathrm{~dB}\left|S_{11}\right| \\
\text { bandwidth (\%) }\end{array}$ & $\begin{array}{c}3 \mathrm{~dB} \text { AR } \\
\text { bandwidth (\%) }\end{array}$ & HPBWs $\left({ }^{\circ}\right)$ & Max gain (dBic) & $\begin{array}{c}\text { Radiation } \\
\text { efficiency (\%) }\end{array}$ \\
\hline \multirow{2}{*}{ Proposed antenna } & \multirow{2}{*}{$0.211 \lambda_{0} \times 0.211 \lambda_{0} \times 0.057 \lambda_{0}$} & 5.5 & 4.2 & 120 & 3.4 & 77 \\
\hline & & 6.1 & 2.6 & 116 & 2.9 & 72 \\
\hline \multirow{2}{*}{ Ref. [5] } & \multirow{2}{*}{$0.23 \lambda_{0} \times 0.23 \lambda_{0} \times 0.07 \lambda_{0}$} & $\geq 20$ & Exact values & $\leq 100$ & 3.6 & 86 \\
\hline & & $\geq 20$ & not specified & $\leq 100$ & 3.8 & 82 \\
\hline \multirow{2}{*}{ Ref. [6] } & \multirow{2}{*}{$0.47 \lambda_{0} \times 0.42 \lambda_{0} \times 0.098 \lambda_{0}$} & 12.7 & 1.9 & $\leq 80$ & 5.0 & Exact values \\
\hline & & 11.4 & 2.1 & $\leq 80$ & 7.0 & not specified \\
\hline \multirow{2}{*}{ Ref. [13] } & \multirow{2}{*}{$0.448 \lambda_{0} \times 0.448 \lambda_{0} \times 0.077 \lambda_{0}$} & 2.3 & 0.6 & $\leq 80$ & 4.3 & Exact values \\
\hline & & 7.2 & 1.4 & $\leq 80$ & 6.4 & not specified \\
\hline \multirow{2}{*}{ Ref. [14] } & \multirow{2}{*}{$0.491 \lambda_{0} \times 0.491 \lambda_{0} \times 0.164 \lambda_{0}$} & 6.3 & 1.9 & $\leq 80$ & 6.3 & 90 \\
\hline & & 22.0 & 7.3 & $\leq 80$ & 7.5 & 97.4 \\
\hline \multirow{2}{*}{ Ref. [16] } & \multirow{2}{*}{$0.368 \lambda_{0} \times 0.368 \lambda_{0} \times 0.122 \lambda_{0}$} & 1.4 & 0.8 & 82 & 7.0 & 95 \\
\hline & & 6.5 & 2.2 & 82 & 6.7 & 87 \\
\hline \multirow{2}{*}{ Ref. [17] } & \multirow{2}{*}{$0.483 \lambda_{0} \times 0.483 \lambda_{0} \times 0.015 \lambda_{0}$} & 2.3 & 0.6 & 100 & 3.9 & Exact values \\
\hline & & 3.0 & 0.7 & 114 & 3.9 & not specified \\
\hline \multirow{2}{*}{ Ref. [21] } & \multirow{2}{*}{$0.52 \lambda_{0} \times 0.52 \lambda_{0} \times 0.224 \lambda_{0}$} & $\geq 10$ & $\geq 10$ & 135 & 4.2 & Exact values \\
\hline & & $\geq 10$ & $\geq 10$ & 112 & 4.2 & not specified \\
\hline
\end{tabular}

from Figure 9(a), with $L_{i 1}$ varying from $7 \mathrm{nH}$ to $9 \mathrm{nH}$, that the resonant frequencies at both bands decrease. The same phenomenon can be found in Figure 9(b) with $L_{i 2}$ varying from $1 \mathrm{nH}$ to $1.4 \mathrm{nH}$ at the high band. But with the increment of $L_{i 2}$, the resonant frequency at the low band changes slightly. It means that by increasing the inductance of the inserted chip inductors, the effective electrical length of the antenna increases; thus, the compactness can be obtained.

\section{Simulated and Measured Results}

The ANSYS High-Frequency Structure Simulator (HFSS) is used to investigate and optimize the antenna configuration. A prototype of the proposed antenna is fabricated and measured as shown in Figure 10. The $\left|S_{11}\right|$ is measured with the Wiltron 37269A vector network analyzer, and the radiation patterns and ARs are measured in an anechoic chamber.

The simulated and measured $\left|S_{11}\right|$ is plotted in Figure 11, and a good agreement can been seen between the simulated and measured results. The measured impedance bands $\left(\left|S_{11}\right|<-10 \mathrm{~dB}\right)$ range from 1.236 to $1.308 \mathrm{GHz}$ and from 1.52 to $1.616 \mathrm{GHz}$, with the relative bandwidths of $5.5 \%$ and $6.1 \%$. The simulated and measured ARs at the boresight direction are plotted in Figure 12. The measured AR bands $(\mathrm{AR}<3 \mathrm{~dB})$ are $54 \mathrm{MHz}(1.232-1.286 \mathrm{GHz})$ and $40 \mathrm{MHz}(1.532-1.572 \mathrm{GHz})$, with the relative bandwidths of $4.2 \%$ and $2.6 \%$.

The simulated and measured radiation patterns at $1.268 \mathrm{GHz}$ and $1.561 \mathrm{GHz}$ are plotted in Figure 13. At $1.268 \mathrm{GHz}$, the proposed antenna yields wide HPBWs of $120^{\circ}$ and $125^{\circ}$ in the XOZ and YOZ planes, while the measured $3 \mathrm{~dB}$ AR beamwidths are $116^{\circ}$ and $120^{\circ}$ in the $\mathrm{XOZ}$ and YOZ planes, respectively, as shown in Figure 14(a). At $1.561 \mathrm{GHz}$, the proposed antenna yields HPBWs of $121^{\circ}$ and $116^{\circ}$ in the XOZ and YOZ planes, while the measured $3 \mathrm{~dB}$ AR beamwidths are $119^{\circ}$ and $115^{\circ}$, respectively, as shown in Figure 14(b). The measured antenna gains at the boresight direction for $1.268 \mathrm{GHz}$ and $1.561 \mathrm{GHz}$ are 3.4 and $2.9 \mathrm{dBic}$, while the measured antenna radiation efficiencies can reach up to $77 \%$ and $72 \%$ as shown in Figure 15, respectively. The radiation efficiencies of the antenna are slightly lower than those of the antennas in the references due to the compactness and the inserted chip inductors. Discrepancies between measured and simulated results are likely due to substrate and measurement errors.

Table 1 shows the comparison of the measured performance of the proposed antenna with those of previous dualband GNSS antennas. As shown in Table 1, the proposed antenna shows a compact dimension with wider HPBWs at both bands compared with other antennas.

\section{Conclusion}

A compact dual-band CP antenna with wide HPBWs for CNSS applications has been proposed and experimentally demonstrated in this paper by adopting the shorting loaded technique and inserting chip inductors. Four compact inverted-F monopoles are arranged symmetrically to the center point and fed by a compact SP feeding network. The proposed antenna exhibits two overlapped impedance and AR bandwidths of $50 \mathrm{MHz}(1.236-1.286 \mathrm{GHz})$ and $40 \mathrm{MHz}(1.532-1.572 \mathrm{GHz})$, covering the CNSS-2 B3 and B1 bands. Meanwhile, the HPBWs at $1.268 \mathrm{GHz}$ and $1.561 \mathrm{GHz}$ are both greater than $115^{\circ}$ with a compact dimension of $0.211 \lambda_{0} \times 0.211 \lambda_{0} \times 0.057 \lambda_{0}$. With these advantages, the antenna can be widely used in CNSS applications.

\section{Conflicts of Interest}

The authors declare that they have no conflicts of interest. 


\section{References}

[1] J. Long and D. F. Sievenpiper, "A compact broadband dualpolarized patch antenna for satellite communication/navigation applications," IEEE Antennas and Wireless Propagation Letters, vol. 14, pp. 273-276, 2015.

[2] M. Chen and C.-C. Chen, "A compact dual-band GPS antenna design," IEEE Antennas and Wireless Propagation Letters, vol. 12, pp. 245-248, 2013.

[3] S. Gupta and G. Mumcu, "Dual-band miniature coupled double loop GPS antenna loaded with lumped capacitors and inductive pins," IEEE Transactions on Antennas and Propagation, vol. 61, no. 6, pp. 2904-2910, 2013.

[4] Nasimuddin, X. Qing, and Z. N. Chen, "A compact circularly polarized slotted patch antenna for GNSS applications," IEEE Transactions on Antennas and Propagation, vol. 62, no. 12, pp. 6506-6509, 2014.

[5] C. Sun, H. Zheng, and Y. Liu, "Compact dual-band circularly polarised GNSS antenna," Electronics Letters, vol. 51, no. 20, pp. 1559-1560, 2015.

[6] T. N. Chang and J. M. Lin, "Corner-fed dual-band circularly polarised antenna," IET Microwaves, Antennas \& Propagation, vol. 8, no. 15, pp. 1423-1431, 2014.

[7] K. Agarwal, Nasimuddin, and A. Alphones, "Triple-band compact circularly polarised stacked microstrip antenna over reactive impedance meta-surface for GPS applications," IET Microwaves, Antennas \& Propagation, vol. 8, no. 13, pp. 1057-1065, 2014.

[8] K. Agarwal and S. Dutta, "Miniaturized circularly polarized stacked patch antenna on reactive impedance surface for dual-band ISM and WiMAX applications," International Journal of Antennas and Propagation, vol. 2015, Article ID 938565, 10 pages, 2015.

[9] K. Zhang, C. Liu, X. Liu, H. Guo, and X. Yang, "Miniaturized circularly polarized implantable antenna for ISM-band biomedical devices," International Journal of Antennas and Propagation, vol. 2017, Article ID 9750257, 9 pages, 2017.

[10] Y. Li, S. Sun, and F. Yang, "A miniaturized Yagi-Uda-oriented double-ring antenna with circular polarization and directional pattern," IEEE Antennas and Wireless Propagation Letters, vol. 12, pp. 945-948, 2013.

[11] M. Ramirez, J. Parron, J. M. Gonzalez-Arbesu, and J. Gemio, "Concentric annular-ring microstrip antenna with circular polarization," IEEE Antennas and Wireless Propagation Letters, vol. 10, pp. 517-519, 2011.

[12] Y. Li, B. Tian, J. Xue, and G. Ge, "Compact dual-band circularly polarized antenna design for navigation terminals," IEEE Antennas and Wireless Propagation Letters, vol. 15, pp. 802-805, 2016.

[13] K. Chen, J. Yuan, and X. Luo, "Compact dual-band dual circularly polarised annular-ring patch antenna for BeiDou Navigation Satellite System application," IET Microwaves, Antennas \& Propagation, vol. 11, no. 8, pp. 1079-1085, 2017.

[14] S. X. Ta, I. Park, and R. W. Ziolkowski, "Dual-band wide-beam crossed asymmetric dipole antenna for GPS applications," Electronics Letters, vol. 48, no. 25, pp. 1580-1581, 2012.

[15] K. Saurav, D. Sarkar, and K. V. Srivastava, "Dual-band circularly polarized cavity-backed crossed-dipole antennas," IEEE Antennas and Wireless Propagation Letters, vol. 14, pp. 5255,2015 .
[16] S. X. Ta and I. Park, "Dual-band operation of a circularly polarized four-arm curl antenna with asymmetric arm length," International Journal of Antennas and Propagation, vol. 2016, Article ID 3531089, 10 pages, 2016.

[17] X. L. Bao and M. J. Ammann, "Dual-frequency dual circularlypolarised patch antenna with wide beamwidth," Electronics Letters, vol. 44, no. 21, pp. 1233-1234, 2008.

[18] Z. N. Chen, W. K. Toh, and X. Qing, "A microstrip patch antenna with broadened beamwidth," Microwave and Optical Technology Letters, vol. 50, no. 7, pp. 1885-1888, 2008.

[19] W. Q. Cao, B. N. Zhang, A. J. Liu et al., “A low-profile CP microstrip antenna with broad beamwidth based on loading with curved microstrip resonant structures," Journal of Electromagnetic Waves and Applications, vol. 26, no. 11-12, pp. 1602-1610, 2012.

[20] Y. X. Sun, K. W. Leung, and K. Lu, "Broadbeam cross-dipole antenna for GPS applications," IEEE Transactions on Antennas and Propagation, vol. 65, no. 10, pp. 5605-5610, 2017.

[21] S. L. Zuo, L. Yang, and Z. Y. Zhang, "Dual-band CP antenna with a dual-ring cavity for enhanced beamwidth," IEEE Antennas and Wireless Propagation Letters, vol. 14, pp. 867-870, 2015.

[22] C.-W. Su, S.-K. Huang, and C.-H. Lee, "CP microstrip antenna with wide beamwidth for GPS band application," Electronics Letters, vol. 43, no. 20, pp. 1062-1063, 2007.

[23] X. Ye, M. He, P. Zhou, and H. Sun, "A compact single-feed circularly polarized microstrip antenna with symmetric and wide-beamwidth radiation pattern," International Journal of Antennas and Propagation, vol. 2013, Article ID 106516, 7 pages, 2013.

[24] S. He and J. Deng, "Compact and single-feed circularly polarised microstrip antenna with wide beamwidth and axial-ratio beamwidth," Electronics Letters, vol. 53, no. 15, pp. 1013-1015, 2017.

[25] S. X. Ta and I. Park, "Compact wideband sequential-phase feed for sequentially rotated antenna arrays," IEEE Antennas and Wireless Propagation Letters, vol. 16, pp. 661-664, 2017. 


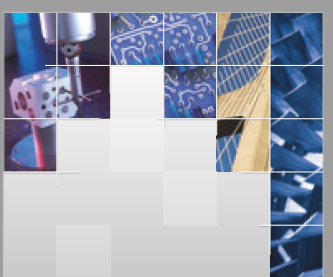

\section{Enfincering}
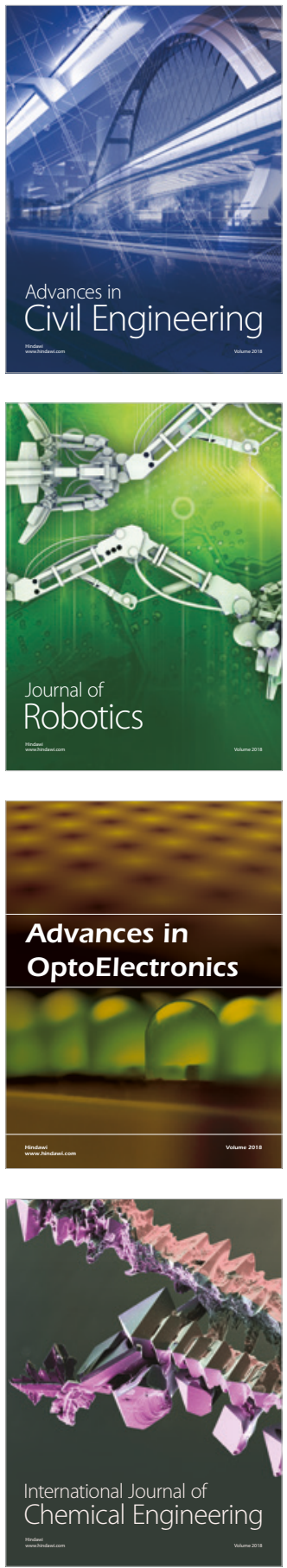

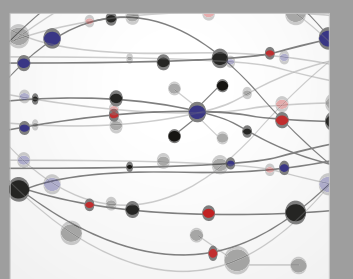

\section{Rotating \\ Machinery}

The Scientific World Journal

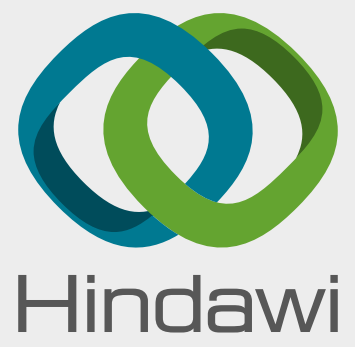

Submit your manuscripts at

www.hindawi.com
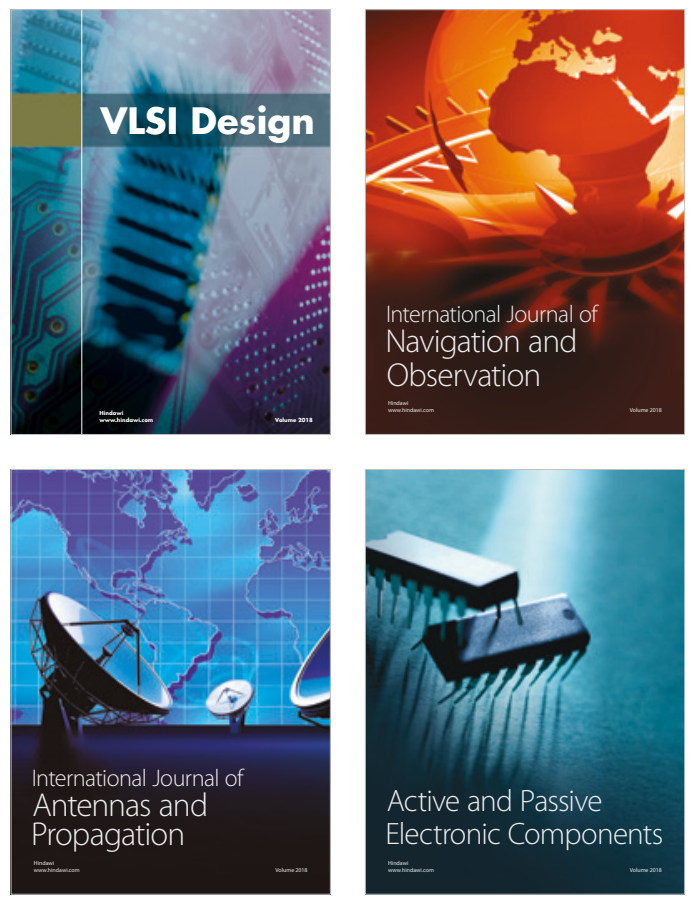
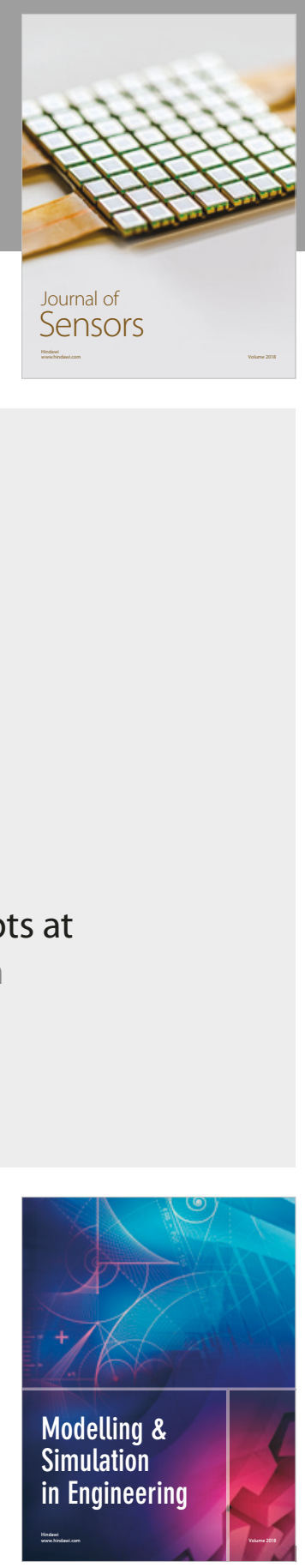

\section{Advances \\ Multimedia}
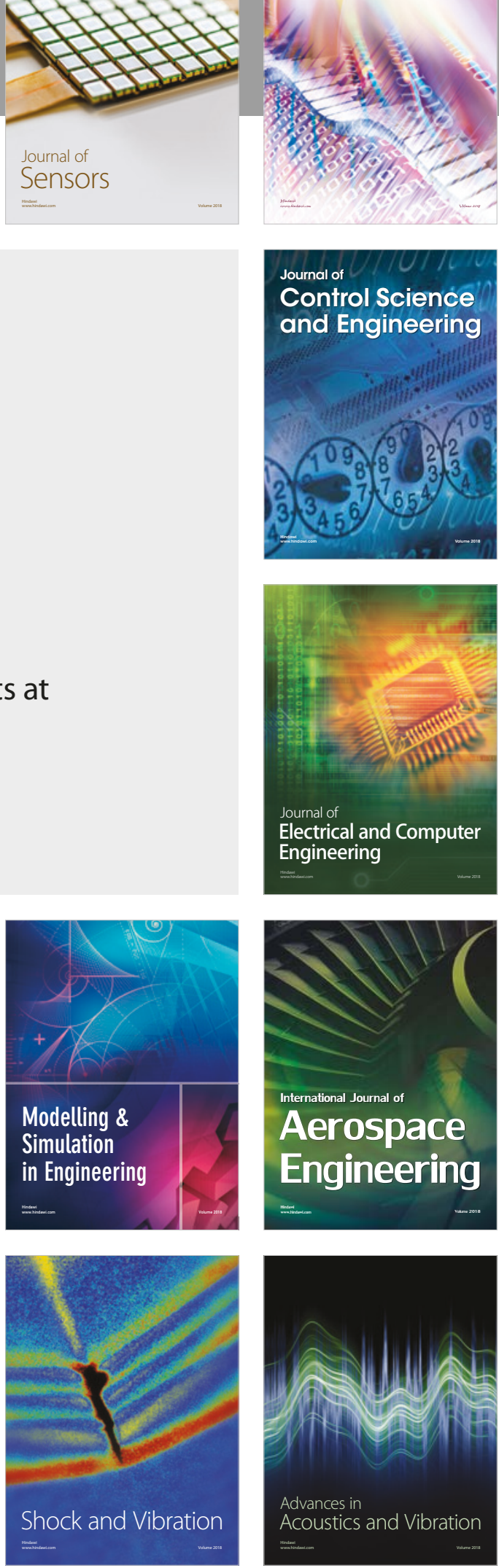